\title{
LA CIUTAT COM A LABORATORI: NOVES CARTOGRAFIES DE LES PRÀCTIQUES MUSICALS CREATIVES
}

\section{Adolf Murillo i Ribes \\ Universitat Politécnica de València (UPV)}

RESUM: Aquest article parteix d'una investigació que enfoca les pràctiques de música experimental col·laborativa. Mitjançant una metodologia etnogràfica se submergeix en aquest tipus de pràctiques musicals que es desenvolupen a la ciutat de València a través d'una mostra de músics experimentals sense formació acadèmica en música. L'estudi d'aquest tipus de pràctiques ens permet visibilitzar unes maneres de fer que entren en conflicte amb l'establishment i es mouen reconfigurant noves xarxes de comunicació i participació a través de l'art sonor, creant noves cartografies culturals i artístiques basades en la col-laboració i en processos creatius que afecten les maneres de concebre, produir i compartir la música.

Paraules Clau: noves pràctiques artístiques, transformació social, noves escoltes, no-músics, música experimental, etnografia.

RESUMEN: Este artículo parte de una investigación sobre las prácticas de música experimental colaborativa. Mediante una metodología etnográfica se sumerge en este tipo de prácticas musicales que se desarrollan en la ciudad de Valencia a través de una muestra de músicos experimentales sin formación musical académica. El estudio de este tipo de prácticas nos permite visibilizar unas maneras de hacer que entran en conflicto con el establishment y se mueven reconfigurando nuevas redes de comunicación y de participación a través del arte sonoro, creando nuevas cartografías culturales y artísticas basadas en la colaboración y en procesos creativos que afectan a las formas de concebir, producir i compartir la música.

PalABRAS ClaVE: nuevas prácticas artísticas, transformación social, nuevas escuchas, no-músicos, música experimental, etnografía. 


\begin{abstract}
This article is based on a study of the practices of experimental collaborative music. An ethnographic study of these music practices was conducted in the city of Valencia, observing a sample of experimental musicians with no academic musical training. The study of this type of music practice reveals certain ways of doing things that come into conflict with the establishment and that work by reshaping new communication and participation networks through sound art, creating new cultural and artistic cartographies based on collaboration and creative processes that affect how music is conceived, produced and shared.
\end{abstract}

KEYWORDS: new artistic practices, social transformation, new listening, non-musicians, experimental music, ethnography.

\title{
Introducció
}

Cempre he sentit la curiositat i l'atracció per entendre com la gent sense cap tipus de formació musical s'enfrontava al repte de crear-la. En algunes ocasions havia tingut l'oportunitat de treballar amb gent sense cap tipus de formació acadèmica i mai deixava de sorprendre'm la seua passió, creativitat i tècnica a l'hora de resoldre qualsevol creació sonora. La meua formació superior al conservatori, basada en una forta instrucció i en unes formes i estils musicals molt definits, em va donar poc d'espai per desenvolupar la meua creativitat. Aquesta educació summament estructurada m'aportà una mirada parcial que amb el temps va solidificar en una mena de closca que m’impedia entendre altres mirades sobre la música i que, a més a més, era constantment reforçada i compartida per la gent que m'envoltava dintre d'aquest context acadèmic.

Però, què hi havia més enllà dels murs? Quines formes d'aprendre i fer música hi havia en aquests tipus de contextos més informals?

Algunes investigacions d'autors com ara Finnegan (2002) i Green (2006, 2008) assenyalaven cap aquesta direcció, aportant llum sobre l'estudi dels músics autodidactes i les seues maneres d'aprendre des dels contextos infor- 
mals. En el meu cas, acostar-me a aquest tipus de persones i col·lectius no sols ens va permetre resoldre aqueixa curiositat, sinó que va suposar trencar amb la rigidesa que m'aportà la meua formació musical acadèmica. Però també, i no menys important, em va permetre redescobrir una nova ciutat. Una ciutat que viu a l'ombra del políticament correcte, que transpira art i que ens revela una nova cartografia ciutadana, altres xarxes i maneres de compartir, que construeix cultura al voltant de la ciutat que ens acull i que, al mateix temps, es transforma des d'uns no espais acadèmics, des d'uns coneixements de no-músics, els quals rizomàticament $\mathrm{i}$ en comunitats de pràctica, van canviant la fisonomia de la ciutat, habitant $\mathrm{i}$ habilitant els seus espais sonors.

\section{Metodologia}

L'interès per apropar-me i comprendre aquestes pràctiques musicals des del seu interior em va portar a escollir la metodologia etnogràfica. Aquesta metodologia facilita una visió holística i propera que ens ajuda a superar el que és obvi. El mètode etnogràfic ajuda de manera significativa a aclarir les realitats socioculturals sobre les quals intervenir, a conèixer millor les condicions empíriques d'existència de les persones i institucions (les quals necessitem avaluar) i suscitar el diàleg entre elles. A causa de les seues intencions epistemològiques, l'etnografia és el tipus de recerca que l'investigador emprèn per fer intel-ligible l'anomalia, o el conjunt d'anomalies de les quals pren consciència mitjançant un exercici d'estranyament. Segons Velasco i Díaz de Rada (1997) en representar un món concret d'experiències, la intenció bàsica de l'etnografia és mostrar un sistema de relacions (causals, però també concurrencials, simbòliques i de qualsevol altre tipus) que ajude a dissoldre l'anomalia provocada per l'estranyament.

En un primer moment vaig començar una recerca per tal de buscar participants que compliren el criteri escollit de músics sense formació. Prenent el concepte de Brian Eno, per referir-nos als músics autodidactes, els anomenarem «no-músics». La definició de Brian Eno té una clara intenció: posa en dubte que el fet de crear música siga patrimoni absolut del compositor format en l'acadèmia, és a dir, la seua actitud suposava una clara provocació i desafi- 
ament a les regles rígides de l'acadèmia $\mathrm{i}$ apostava per la creativitat $\mathrm{i}$ la lliure opció de fer música sense haver de passar per un motlle concret.

Els primers intents per trobar una mostra de participants van ser infructuosos i no perquè fóra complicat trobar no-músics; simplement, trobar informants amb predisposició a col·laborar en un procés d'investigació de vegades és complicat. Durant aqueix temps de recerca per fi vaig contactar amb el nostre informant principal, Edu Comelles, qui alhora va fer la funció de porter, facilitant el contacte amb la resta de participants de la investigació.

La primera selecció d'informants formada per cinc no-músics, va permetre apropar-me a un grup de músics que conformaven una comunitat de pràctica al voltant de la lliure improvisació: 1'Orquestra Mundana. Com afirma Galiana (2014), l'Orquestra Mundana més que una orquestra esdevé un autèntic laboratori, on de forma dialògica, es comparteix, s'inventa, s'experimenta, es descobreixen i s'apliquen noves formes de crear música en temps real i a través de la lliure improvisació. Aquesta aproximació a l'Orquestra Mundana ens va permetre estudiar aquestes pràctiques des de la interacció del grup, teixint una complexa trama fonamentada en la col·laboració que es construeix des de les diferències individuals.

El treball de camp va ser realitzat durant sis mesos seguint el cicle natural de la seua proposta de concerts itinerants Off_hz que travessava la ciutat oferint una programació fresca i creativa a diferents galeries d'art de la ciutat de València.

Off_Herzios és un circuit itinerant d'art sonor i músiques estranyes. La iniciativa, promoguda des d'Audiotalaia, un netlabel igualment centrat en l'art sonor, pretén eixir dels contextos tradicionals del concert o el festival, per construir nous ponts de diàleg $i$ intercanvi entre els diferents espais sempre amb la mirada posada a fer arribar propostes experimentals i de músiques estranyes a nous públics i audiències. (Galiana, 2014: 275)

Dintre de les estratègies que ens aporta aquesta metodologia vaig escollir l'observació participant. Aquesta estratègia ens va donar l'oportunitat de conèixer des d'una posició privilegiada diversitat de formes d'abastar la creació musical i ens va permetre introduir-nos a l'interior de les seues experiències conformades pels seus anhels, incerteses, lluites i, com podria ser d'altra manera, les seues fortaleses. L'observació participant va estar combinada amb 
una sèrie d'entrevistes semiestructurades que em van permetre d'aprofundir en les particularitats individuals de cada participant i facilitaven una millor interpretació a través de la triangulació de les dades des de l'encreuament de diferents mètodes de producció de la informació.

Durant aquest treball de camp la informació recollida va ser analitzada a través d'una anàlisi temàtica i codificada fent ús del sistema d'anàlisi qualitatiu Atlas-ti.

\section{Resultats}

Els resultats d'aquesta investigació ens permeten dibuixar unes noves cartografies al voltant de les pràctiques musicals experimentals que evidencien noves formes de fer i viure la música. Per tant, allò que he observat i estudiat supera la visió d'unes estructures que, ja en descomposició, no encaixen amb les necessitats ni demandes de la societat contemporània del segle XXI. Unes estructures que han afavorit i prioritzat — al caliu de la subvenció - unes formes culturals programades «des del despatx», provocant la pervivència d'unes estructures rígides $\mathrm{i}$ jeràrquiques que han negat la presència de les altres músiques i de moltíssimes propostes culturals contemporànies que posen de manifest altres formes, nous models organitzatius que evidencien una horitzontalitat en les seues formes internes de relacionar-se i que rizomàticament abasten territoris que, malgrat la seua invisibilitat, conformen el magma d'un capital cultural que revitalitza barris i ciutats i crea nous espais. Aquest intangible cultural i creatiu ha estat ocult moltes vegades $i$ ha funcionat paral·lelament a altres circuits que l'administració ha afavorit $i$ ha tingut en compte.

La complexitat dels seus entramats, basats en una col·lectivitat creativa, ha resultat difícil de mesurar i detectar per la pesant maquinària administrativa que, capficada en altres models organitzatius, sembla cega davant les manifestacions emergents.

En aquest sentit, la cultura com a motor que activa els processos d'innovació social i els discursos al seu voltant es presenten com a agents de canvi $i$ actors actius en el desenvolupament econòmic, cultural i social, creant un escenari favorable per a la creació de projectes i iniciatives artístiques de 
caràcter experimental que incrementen el potencial creatiu a tots els nivells. Podem dir que allò que hem observat tendeix més cap a una nova cultura basada en la multiplicació d'esdeveniments que funcionen com a nodes perfectament interconnectats davant d'una cultura de grans esdeveniments que a hores d'ara podem definir com devastadora a escala econòmica i cultural.

Aquests punts de confluència funcionen com a catalitzadors i a través de propostes que tenen el seu origen en accions artístiques que s'arrelen als barris $\mathrm{i}$ als moviments associatius, les persones que hi participen aporten experiències en forma de noves narratives que van interconnectant-se d'una manera exponencial cap a direccions múltiples. Aquestes narratives abasten des del pròxim i local fins a altres nodes més globals. Les seues formes de fer, filles dels temps líquids (Bauman, 2010), es mouen sense fronteres, també a través de les xarxes virtuals, però partint en molts casos des de vivències físiques, on la fricció i la hibridació artística detonen constantment fent-se visibles a través d'accions sonores summament creatives. Aquest magma o viver ens trasllada cap a noves formes participatives on un art de proximitat, més humanitzat, reforça la tendència d'una nova època on el ciutadà deixa de ser un agent passiu per transformar-se en un ciutadà compromès amb les formes artístiques que a través de petites accions facilita el seu apoderament i es converteix al mateix temps en un potent dispositiu pedagògic que ens educa contínuament sense preguntar-nos la nostra condició social.

En el panorama de les arts es fa cada vegada més evident el paper dels artistes i de les institucions en la construcció permanent de l'ecosistema creatiu; molts projectes afavoreixen processos d'investigació que s'allunyen de la producció d'objectes sagrats i potencien noves metodologies i eines diferents que permeten fer front a problemàtiques socials i plantejar noves formes d'interacció entre les persones i el seu entorn: les noves metodologies i eines digitals aporten una ampliació tant de la pràctica artística com de la redefinició del paper i de la resposta de les institucions.

La seua visió de la cultura prototípica els du al rebuig a la rutina, a fer amb una actitud de canvi constant que permeta el flux dinàmic de noves propostes generadores de coneixement. Són una mostra de la potencialitat de la intel·ligència col·lectiva (Lévy, 2004, 2007) i, segons els casos, empren la música com a catalitzador de nous projectes que van molt més enllà de les propostes 
locals i tenen la capacitat de produir friccions — sense connotacions pejoratives, perquè la fricció ocasiona interrogants $\mathrm{i}$ intents de resposta - i noves connexions entre diferents nodes distribuïts.

En les seues actituds és visible l'interès per una nova sensibilització de l'art sonor, sensibilització que no sols ve donada per la diversitat d'estils i estètiques que amb tota normalitat creixen i s'hibriden els uns amb els altres, sinó que també permet aprofitar cada context físic interrelacionant música i context, apropant-nos i generant un altre posicionament en l'acció d'escoltar.

La sensibilització reivindicada, afavorida per una nova situació, els permet habitar de nou els espais que conformen la ciutat. Les seues músiques dels no-músics en general, però especialment la de Llorenç Barber, aposten per una escolta que rescata la ciutat com a un instrument sonor més i la redefineixen, propiciant unes formes que ens fan conscients dels espais on es produeixen i integren les sonoritats que no poden ser controlades: lladrucs, trànsit, clàxons de cotxes, sirenes de policia, persianes dels comerços, veus dels vianants... de la ciutat, amalgamant-les en un tot sònic on l'oient explora lliurement, submergint-se alhora en l'espai i el so, que donen com a resultat una nova dimensió de l'escolta que ens convida a sentir i viure la ciutat $\mathrm{i}$ els espais que la conformen d'una altra manera, aportant noves percepcions, sensacions i reflexions sobre l'entorn que habitem. Aquesta mirada encaixa perfectament amb la visió que aporten els autors Estrela i Martínez (2014) al voltant de les potencialitats pedagògiques de la ciutat.

I quan ens referim a la ciutat, parlem del complex cultural que suposa la metròpoli contemporània, i per tant parlem de la seua estructura física, però sobretot del seu imaginari. Amb això ens acostem a la idea del currículum de la ciutat, és a dir, al reconeixement de la ciutat com un espai en el qual es conjuguen sabers i experiències que es representen als seus carrers i places, però també a les seues dinàmiques, tradicions i narratives, els quals ens construeixen com a ciutadans. (p. 217)

Aquestes pràctiques generen noves relacions creador-oient-espai. Els escenaris són vistos com els nodes d'una rica xarxa, on creador i públic estableixen noves relacions basades en la proximitat, el diàleg i la construcció de coneixement.

L'artista, com un ciutadà més, es mostra coneixedor del que fa i alhora ignorant (Rancière, 2002), ja que no és posseïdor de la veritat absoluta que 
l'aproparia a una visió de l'art com a objecte o com a obra d'art total (Dewey, 2004, 2008).

Aquesta visió sacseja el concepte de «lloc sacre», encarnat en l'auditori, un espai asèptic on s'afavoreix en moltes ocasions una cultura desconnectada dels problemes, la quotidianitat codificada del ciutadà del carrer i ens llança a noves aventures més arrelades i contextualitzades en el quefer quotidià.

\section{Discussió/conclusions}

He pogut veure i sentir de les seues pròpies veus com l'administració ha negat sistemàticament la pluralitat cultural i especialment la pluralitat d'unes músiques que, situades en la perifèria de les músiques acceptades i reconegudes per l'estatus, no troben el seu lloc. L'administració, amb les seues xarxes i circuits, continua facilitant i potenciant unes músiques majoritàriament arrelades a les elits, amb noms i cognoms, en contra d'una música que és patrimoni del talent col·lectiu.

He pogut gaudir de les seues propostes i projectes, i m'he sentit part d'una comunitat i dels seus somnis, però també he pogut veure i viure la precarietat dels espais, la falta de condicions mínimes per tal de desenvolupar dignament el seu treball; he vist com els assumptes econòmics, sempre imprescindibles, s'han reduït gairebé al no-res o, fins i tot, se solucionen amb la cessió de les instal·lacions, però que tot això no ha estat cap impediment per tirar endavant cadascun dels projectes realitzats.

Davant d'aquestes situacions precàries o del tancament dels espais que en el seu dia foren viver de propostes creatives, aquests col·lectius, lluny de desintegrar-se, es reinventen en noves formes de compartir de manera itinerant, travessant la ciutat $\mathrm{i}$ aprofitant les galeries d'art, revitalitzant-les amb noves i suggeridores propostes.

Davant el tancament d'espais, la resposta és crear més espais, nous formats, emprendre en lloc de suspendre.

La seua actitud emprenedora els empenta a reinventar-se en cada acció que enceten. L'heterogeneïtat, la barreja d'estils i les formes d'encaixar-los ens parlen d'altres formes més humanes i dialògiques de créixer en la diver- 
sitat i des de l'adversitat. El caràcter divers els fa més forts, potencia i augmenta la col·laboració fent-los més permeables, esborrant les fronteres entre les disciplines artístiques i guanyant nous sectors d'audiència procedent d'una franja social que, aparentment, no estava interessada en les propostes administratives oficials.

La música, més enllà d'una professió —que també ho és- ens mostra en el seu dia a dia altres possibilitats: la música a l'abast de tothom és una experiència que enriqueix $\mathrm{i}$ farceix de reflexions $\mathrm{i}$ creativitat cada acte quotidià (Ferrando, 2013).

Les seues formes de fer i viure la música, legítimes com qualsevol acte d'expressió artística, han de ser vistes com a elements potencials que ajuden a configurar nous mapes culturals que faciliten la creació i aprofitament d'altres espais, reorienten les polítiques culturals que es vertebren des de sota que generen noves actituds i posicionaments davant formes d'expressió més minoritàries, les quals potencien les fórmules inclusives i integradores a partir d'una multiplicitat d'actors, sense tenir en compte la seua condició sociocultural.

\section{A mode de conclusió}

S'ha evidenciat al llarg de l'estudi que, més enllà de la necessària conflictivitat existent, altres maneres més dialògiques i consensuades tenen la potencialitat de construir nous entramats que s'estenen de forma multidireccional des de les petites col-laboracions que abasten nous territoris imaginaris i geogràfics, físics i virtuals, integrant-los gràcies a les col·laboracions que van més enllà de la música, i ens transporten i ubiquen en espais on els llenguatges es fusionen, creant-ne de nous.

Les seues pràctiques representen l'apoderament ciutadà que ja no es conforma amb l'antic model, i presenten un ciutadà prosumidor que és partícip de les propostes i té la capacitat de teixir noves relacions i formes distributives de la cultura, aportant una font refrescant d'innovació social molt important i necessària. 
Posar la mirada en aquest tipus de col·lectius aporta solucions eficaces per tal d'enfortir el teixit social i cultural de les ciutats a través d'una cultura més participativa i, si em permeteu, molt més creativa.

Fer visibles les potencialitats i la capacitat de transformació cultural que conciten aquests col·lectius hauria d'afavorir noves polítiques culturals que ens hi arrelen i transformen cada racó de les ciutats.

No solament s'ha fet evident la precarietat pel que fa als espais i les condicions mínimes que necessiten aquests col·lectius, també hem pogut viure i sentir la seua preocupació per la sostenibilitat dels projectes. Són uns collectius que, acostumats a treballar amb els mínims, supleixen les mancances econòmiques amb voluntat i passió per traure endavant el que pensen fer, $\mathrm{i}$ necessiten una administració molt més àgil i compromesa per a facilitar-los la continuïtat i el creixement, que reconega la importància dels corrents emergents i que es faça càrrec de les seues reivindicacions.

És evident que l'administració ha estat massa aliena a tota aquesta diversitat cultural que, per si sola, s'ha constituit com un referent a escala nacional de les músiques experimentals hibridades amb altres manifestacions artístiques, culturals i cíviques. Cal una revisió de la política cultural que, arribat aquest moment, ha de ser molt més permeable i atenta amb totes les formes $\mathrm{i}$ manifestacions artístiques diverses, perquè són la mostra que revela la riquesa d'un poble, d'una comunitat i d'un grup, aportant-nos elements crítics i reflexius que funcionen com a lent amplificadora de la diversitat i l'audàcia del pensament humà.

Les seues pràctiques han de ser aprofitades com a potencials connectors que posen en comú a associacions informals, altres institucions, grups artístics i persones amb diferents graus de participació que aporten valors des de la flexibilitat i l'autonomia de moviment i gestió que els caracteritza.

Les administracions han de superar l'antic model estàtic $i$ jeràrquic per apropar-se a altres formes consensuades i participatives que encabisquen les propostes que es generen en aquests col·lectius. En el nou paradigma que s'obri pas, l'administració ha de tenir un paper fonamental que, en lloc d'imposar visions unívoques, ajude a visibilitzar i desenvolupar iniciatives inèdi- 
tes, dotant-les de la legitimitat que els pertoca i que fins ara ha estat ignorada, minimitzada o negada.

La capacitat pedagògica de les seues pràctiques ha d'aprofitar per a oferir-nos als ciutadans una formació que ajude a superar la ruptura entre l'art contemporani i el nou públic prosumidor (Toffler, 2004; Tapscott, 1995). Les pràctiques estudiades proposen que és possible superar l'escletxa afavorint la proximitat i la implicació directa del públic en l'art contemporani, l'ús i l'aprofitament dels espais que s'adapten i s'humanitzen amb permeabilitat a noves propostes, l'aprofitament de les xarxes i entramats que ja existeixen i constitueixen el teixit viu de la ciutat, l'acceptació de tot allò que és divers.

Fer visibles les potencialitats d'aquestes pràctiques musicals creatives ha de ser vist com una contribució d'aquest estudi per tal de reivindicar la importància d'un treball cultural moltes vegades ocult i oblidat. Així mateix, cal establir i facilitar les connexions amb l'administració per tal d'ajustar i reequilibrar les polítiques culturals que han d'aprofitar el capital humà $\mathrm{i}$ creatiu que hi ha al darrere d'aquestes pràctiques i que, afortunadament, ja es desborden.

\section{Referències}

Bauman, Z. (2010): Tiempos líquidos. Vivir en una época de incertidumbre, Tusquets, Barcelona.

Dewey, J. (2008): El arte como experiencia, Paidós, Barcelona.

Dewey, J. (2002): Experiencia y educación, Biblioteca Nueva, Madrid.

Estrela, C. M. i B. J. Martínez (2014): «Aprendre a la ciutat a través de la deriva», Revista Kult-ur, vol. I, núm. 1, pp. 215-222.

Ferrando, B. (2013): Arte y cotidianidad. Hacia la transformación de la vida en arte, Ardora, Madrid.

Finnengan, R. (2002): «¿Por qué estudiar música? Reflexiones de una antropóloga desde el campo», Revista Trans (Revista transcultural de música). Consulta en línia: <http://www.sibetrans.com/trans/articulo/224/por-que-estudiar-la-musica-reflexiones-de-una-antropologa-desde-el-campo>. 
Galiana, J. L. (2014): La emoción sonora. De la creación electroacústica, la improvisación libre, el arte sonoro y otras músicas experimentales, Piles, València.

Green, L. (2006): «Popular music education in and for itself, and for other music: corrent research in the classroom», International Jounal of Music Education, 24 (2), 101-108.

Green, L. (2008): Music, informal learning and the school: A new classroom pedagogy, Ashgate, Aldershot, UK.

LÉvy, P. (2004): «Inteligencia colectiva: por una antropología del ciberespa-

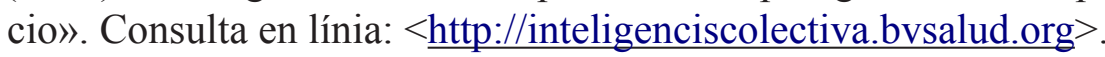

LÉvy, P. (2007): Cibercultura: La cultura de la Sociedad digital, Anthropos, Barcelona.

RANCIÈRE, J. (2002): El maestro ignorante, Laertes, Barcelona.

TAPScotт, D. (1995): The digital economy, McGraw-Hill, London.

Toffler, A. (2004): La tercera ola, Plaza \& Janés, Madrid.

Velasco, H. i A. Díaz de Rada (1997): La lógica de la investigación etnográfica, Trotta, Madrid. 